\title{
Altered TNFAIP3 mRNA expression in peripheral blood mononuclear cells from patients with rheumatoid arthritis
}

\author{
ZHAOYAN WANG $^{1 *}$, ZONGLIANG ZHANG $^{2 *}$, JIANGSHUI YUAN $^{1}$ and LI LI ${ }^{1}$ \\ ${ }^{1}$ Clinical Laboratory, ${ }^{2}$ Department of Urology, Qingdao Municipal Hospital, Qingdao, Shandong 266011, P.R. China
}

Received March 9, 2015; Accepted May 21, 2015

DOI: $10.3892 /$ br. 2015.486

\begin{abstract}
The tumor necrosis factor $\alpha$-induced protein-3 (TNFAIP3) gene functions in negative immunoregulation and its single-nucleotide polymorphisms (SNPs) are associated with rheumatoid arthritis (RA) disease. However, its expression level in immune cells from RA patients remains unclear. The aim of the present study was to investigate whether the expression of TNFAIP3 is changed in patients with RA. Reverse transcription-quantitative polymerase chain reaction analysis was used to determine TNFAIP3 mRNA expression in peripheral blood mononuclear cells (PBMCs) from patients with RA and healthy controls. TNFAIP3 expression was decreased in RA patients compared with the healthy controls. The expression level of the TNFAIP3 gene negatively correlated with the RA score, anti-cyclic citrullinated peptide (CCP) antibody levels and C-reactive protein levels. Furthermore, RA patients with positive results of anti-CCP antibodies had a lower expression of TNFAIP3 than those without anti-CCP antibodies. In conclusion, the present results suggest that the insufficient expression of the TNFAIP3 gene in PBMCs may correlate with the diagnosis of RA.
\end{abstract}

\section{Introduction}

Rheumatoid arthritis (RA) is a common chronic inflammatory disease that predominantly affects the small joints of the hands and feet (1). The propagation of inflammation is characterized by migration of mononuclear cells into the local inflammatory

Correspondence to: Dr Jiangshui Yuan or Professor Li Li, Clinical Laboratory, Qingdao Municipal Hospital, 1 Jiaozhou Road, Qingdao, Shandong 266011, P.R. China

E-mail: yjsqd1979@163.com

E-mail: 1586574632@qq.com

*Contributed equally

Key words: rheumatoid arthritis, reverse transcription-quantitative polymerase chain reaction analysis, tumor necrosis factor $\alpha$-induced protein-3 sites, leading to the hyperplasia of fibroblast-like synoviocytes (FLSs) primarily due to resistance to apoptosis and damage to cartilage and bone (2). The chronic inflammation is attributed to breakdown of immune homostasis, which results in activation of immune cells and elevation of pro-inflammatory cytokines (3). The immune activation leads to deposition of immune complexes and mononuclear cell infiltration into susceptible organs, while the pro-inflammatory cytokines are responsible for maintenance of the immune activation (4). The major mediators of chronic inflammation in RA include tumor necrosis factor $\alpha$ (TNF- $\alpha$ ), interleukin (IL)-1 $\beta$, IL-6, IL-8 and prostaglandin E2 (5). Induction of pro-inflammatory mediators requires activation of the nuclear factor $(\mathrm{NF})-\kappa \mathrm{B}$ inducing kinase- or inhibitor of NF- $\kappa \mathrm{B}(\mathrm{I} \kappa \mathrm{B})$ kinase-mediated $\mathrm{NF}-\kappa \mathrm{B}$ signal transduction pathways $(6,7)$. The transcription factor $\mathrm{NF}-\kappa \mathrm{B}$ has been well recognized as a key regulator of inflammation in RA (8-10).

TNF- $\alpha$-induced protein-3 (TNFAIP3) is an important negative immunoregulatory gene. TNFAIP3 is a dual ubiquitin-editing enzyme, whose expression is induced by a large number of stimuli in a wide variety of cells (11). Evidence from animal models indicates that TNFAIP3 is a plausible candidate gene in RA susceptibility (11). In TNFAIP3 knockout mice, its deficiency leads to death shortly following birth by severe inflammation and tissue damage in multiple organs $(12,13)$. In immune cells, overexpression of TNFAIP3 can terminate NF- $\mathrm{NB}$ signaling transduced from TNF receptors, toll-like receptors, nucleotide-binding oligomerization domain containing 2 receptors or T cell receptors $(14,15)$. The zinc-finger protein A20 is encoded by an immediate early response gene and acts as a potent I $\mathrm{B}$ signaling pathway (13). Of note, the expression of TNFAIP3 itself is under the control of $\mathrm{NF}-\kappa \mathrm{B}$, suggesting that TNFAIP3 is involved in the negative-feedback regulation of $N F-\kappa B$ activation (13). TNFAIP3-deficient mice develop severe inflammation, which includes inflammation of the joints (16).

Although there is an association between single-nucleotide polymorphisms (SNPs) of the TNFAIP3 gene and RA disease (17-19), the expression level of TNFAIP3 in immune cells from RA patients is not clear. Therefore, the expression of TNFAIP3 mRNA was compared in peripheral blood mononuclear cell (PBMC) between RA patients and healthy controls and the association between TNFAIP3 expression level and disease activity was analyzed in order to elucidate the role of TNFAIP3 expression in the pathogenesis of RA. 


\section{Materials and methods}

Human subjects. A total of 48 patients of Northern Han Chinese descent with RA that was initially diagnosed according to the criteria of the American College of Rheumatology (ACR) and European League Against Rheumatism (EULAR) (2010) were enrolled. At the same time, 41 healthy controls were recruited, who were ethnicity, gender- and age-matched with the patients and did not have any rheumatological conditions. RA score, including joint involvement, serology, duration of symptoms and acute phase reactants for diagnostic purposes, was assessed using the RA classification criteria and scoring system revised by ACR/EULAR in 2010 (20). Peripheral bloods were sampled from all the patients prior to the administration of any immunosuppressive drug to exclude the influence of the drug on TNFAIP3 expression. All the blood samples from the patients and healthy controls were used with informed consent and approval from the Ethics Committee of Qingdao Municipal Hospital (Qingdao, Shandong, China). The characteristics of the patients and healthy subjects are shown in Table I.

Laboratory measurement. For all the RA patients, serum levels of $\mathrm{C} 3, \mathrm{C} 4$, immunoglobulin $\mathrm{G}(\operatorname{IgG}), \operatorname{Ig} \mathrm{A}, \operatorname{Ig} \mathrm{M}$, rheumatoid factor (RF) and C-reactive protein (CRP) were analyzed by an automatic nephelometric immunoassay analyzer (Siemens, Munich, Germany). Anti-keratin antibody (AKA) was analyzed by the indirect immunofluorescent assay (Euroimmun AG, Lübeck, Germany). Anti-cyclic citrullinated peptide $(\mathrm{CCP})$ antibodies were detected using the quantitative enzyme-linked immunoabsorbent assay according to the instructions of the manufacturer (Euroimmun AG). For all the subjects, including the patients and healthy controls, erythrocyte sedimentation rates were determined by Westergren test (Monitor-J+ analyzer; Electa Lab Srl, Forli, Italy).

Preparation of PBMCs and extraction of RNA. Peripheral blood was sampled in sodium citrate-containing cell preparation tubes. PBMCs were separated by density gradient centrifugation from the peripheral blood anticoagulated with sodium citrate. Total RNA was extracted from PBMCs $\left(5 \times 10^{5}\right)$ using TRIzol (Takara, Dalian, China) and treated with RNase-free DNase (Sangon Biotech Inc., Shanghai, China) to remove genomic DNA contamination. RNA $(1 \mu \mathrm{g})$ was reversely transcribed to cDNA using a reverse transcription system kit (Sangon Biotech Inc.) for each sample, and subsequently quantified by photometrical measurement.

Reverse transcription-quantitative polymerase chain reaction (RT-qPCR). The expression of TNFAIP3 mRNA was evaluated by qPCR in triplicate and the level of $\beta$-actin mRNA was also detected as an internal control. qPCR was performed using the SYBR-Green I qPCR kit in accordance with the manufacturer's instructions (Takara) in an ABI PRISM ${ }^{\circledR} 7500$ Sequence Detection System (Perkin-Elmer, Norwalk, CT, USA). Amplification conditions were as follows: $95^{\circ} \mathrm{C}$ for $10 \mathrm{sec}$, followed by 40 cycles of $95^{\circ} \mathrm{C}$ for $5 \mathrm{sec}$ and $60^{\circ} \mathrm{C}$ for $40 \mathrm{sec}$. Primers were synthetized as described by $\mathrm{Li}$ et al (3). The primers used were as follows: TNFAIP3 forward, 5'-CGT CCAGGTTCCAGAACACCATTC-3' and reverse, 5'-TGC
Table I. Demographic characteristics, clinical features and laboratory measurements of the studied subjects.

\begin{tabular}{lcc}
\hline Characteristics & $\begin{array}{c}\text { RA patients } \\
(\mathrm{n}=48)\end{array}$ & $\begin{array}{c}\text { Healthy controls } \\
(\mathrm{n}=41)\end{array}$ \\
\hline $\begin{array}{l}\text { Demographic } \\
\text { characteristics }\end{array}$ & & \\
Female, no. $(\%)$ & $40(83)$ & $33(80)$ \\
Male, no. $(\%)$ & $8(17)$ & $8(20)$ \\
Age, years (range) & $35(19-50)$ & $33(20-51)$ \\
Clinical features & & \\
RA standard rating & $8(6-10)$ & - \\
Laboratory & & \\
measurements & & - \\
C3, g/l & $1.1(0.9-1.9)$ & - \\
C4, g/l & $0.2(0.1-0.5)$ & - \\
IgG, g/l & $15.5(7.0-35.2)$ & - \\
IgA, g/l & $1.1(0.7-4.0)$ & - \\
IgM, g/l & $1.3(0.4-2.3)$ & - \\
RF, IU/ml & $352(28-734)$ & - \\
CRP, mg/l & $54(5-198)$ & - \\
AKA, no. $(\%)$ & $13(27)$ & - \\
Anti-CCP Ab, U/ml & $305(58-1,892)$ & $8(3-20)$ \\
ESR, mm/h & $58(10-142)$ &
\end{tabular}

Values are mean (range), unless stated. RA, rheumatoid arthritis; CCP, cyclic citrullinated peptide; AKA, anti-keratin antibody; RF rheumatoid factor; ESR, erythrocyte sedimentation rate; IgG, immunoglobulin $\mathrm{G}$; Ab, antibody.

GCTGGCTCGATCTCAGTTG-3'; and $\beta$-actin forward, 5'-GACTACCTCATGAAGATCCTCACC-3' and reverse, 5'-TCTCCTTAATGTCACGCACGATT-3'. Each sample was run in triplicate. The PCR products were run in an agarose gel and were in all cases confined to a single band of the expected size. A melting-curve analysis was also performed to ensure the specificity of the products. The expression of the TNFAIP3 gene was normalized to $\beta$-actin and the relative mRNA expression of TNFAIP3 was determined using the comparative $\left(2^{-\Delta \Delta \mathrm{C} t}\right)$ method.

Statistical analysis. Statistical analysis was performed in the SPSS 13.0 software (SPSS, Inc., Chicago, IL, USA). Data are expressed as the mean \pm standard deviation. The difference in TNFAIP3 mRNA level between subject groups was analyzed using the Student's t-test independently. Correlations analysis was performed using the Spearman's rank test. $\mathrm{P}<0.05$ was considered to indicate a statistically significant difference. Figs. 1-5 were generated with the GraphPad Prism software, version 5.0 (San Diego, CA, USA).

\section{Results}

Laboratory measurements of the patients with RA. The demographic characteristics, clinical manifestation and laboratory measurements in the RA patients are presented in Table I. The 


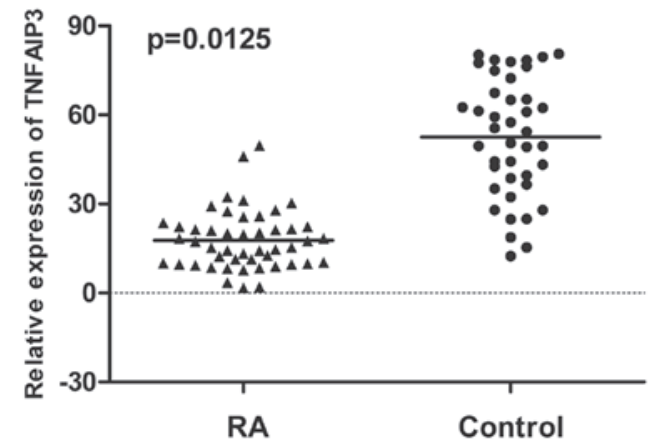

Figure 1. Tumor necrosis factor $\alpha$-induced protein-3 (TNFAIP3) mRNA expression levels from rheumatoid arthritis (RA) patients and controls. Reverse transcription-quantitative polymerase chain reaction was performed to quantify the expression of the TNFAIP3 gene from RA patients $(\mathrm{n}=48)$ and controls $(\mathrm{n}=41)$. Horizontal lines indicate means (21.32 in the patient group; 52.58 in the control group). There is a significant decrease in TNFAIP3 expression in RA patients compared with that of the controls $(\mathrm{P}=0.0125)$.

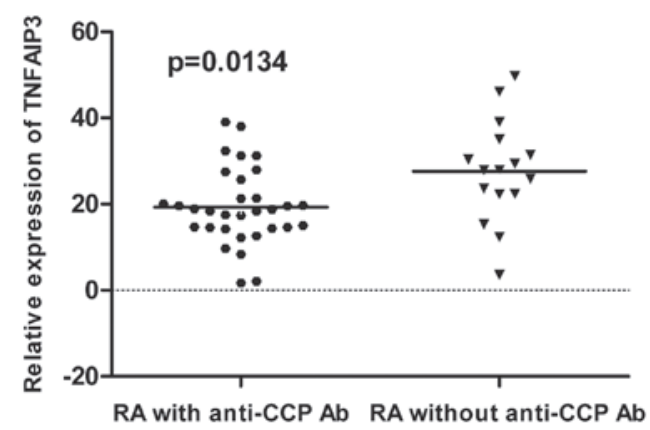

Figure 2. Tumor necrosis factor $\alpha$-induced protein-3 (TNFAIP3) mRNA expression levels in rheumatoid arthritis (RA) patients with and without anti-cyclic citrullinated peptide (CCP) antibodies (Ab). Reverse transcription-quantitative polymerase chain reaction was performed to quantify the expression of the TNFAIP3 gene from RA patients with $(\mathrm{n}=32)$ and without $(\mathrm{n}=16)$ anti-CCP Ab. Horizontal lines indicate means (19.44 in RA patients with anti-CCP Ab; 27.67 in RA patients without anti-CCP Ab). There is a significant decrease in TNFAIP3 expression in RA patients with positive anti-CCP Ab compared with those without anti-CCP Ab $(\mathrm{P}=0.0134)$.

positive results of anti-CCP antibodies, RF and AKA in the RA patients were found in 32, 34 and 13 patients, respectively. The mean value of the RA standard rating score was 7.56 (range, 6-10). The mean value of anti-CCP antibodies for the patients was $305 \mathrm{U} / \mathrm{ml}$ (range, 58-1,892 U/ml). The mean value of CRP for the patients was $54.4 \mathrm{mg} / \mathrm{l}$ (range, $5-198 \mathrm{mg} / \mathrm{l}$ ).

Quantification of TNFAIP3 $m R N A$ expression in PBMC from $R A$ patients and healthy controls by $R T-q P C R$. The expression of TNFAIP3 mRNA in PBMC from 48 RA patients and 41 gender- and age-matched healthy controls was examined using RT-qPCR. The mean of TNFAIP3 mRNA expression in PBMC from RA patients (21.32) was significantly decreased compared to healthy controls (52.58) $(\mathrm{P}=0.0125)$ (Fig. 1). In addition, the expression of TNFAIP3 mRNA in RA patients with the positive result of anti-CCP antibodies (19.44) was significantly lower than in those without a positive result of anti-CCP antibodies (27.67) ( $\mathrm{P}=0.0134)$ (Fig. 2).

Analysis of the associations between TNFAIP3 mRNA expression and the characteristics or laboratory parameters in the

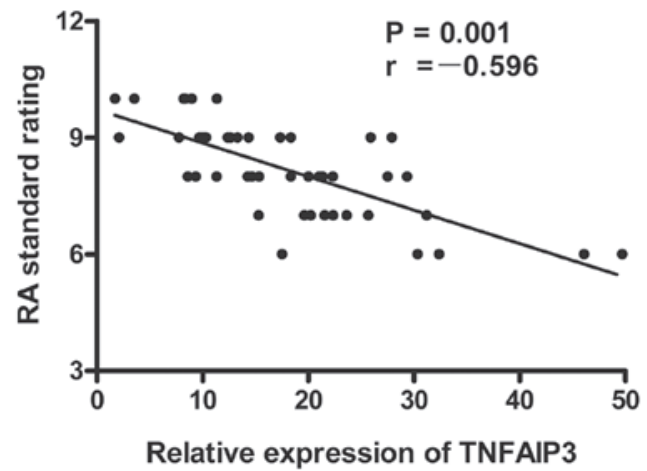

Figure 3. Negative correlation between tumor necrosis factor $\alpha$-induced protein-3 (TNFAIP3) mRNA expression levels and rheumatoid arthritis (RA) standard rating for all the RA patients $(n=48)$.

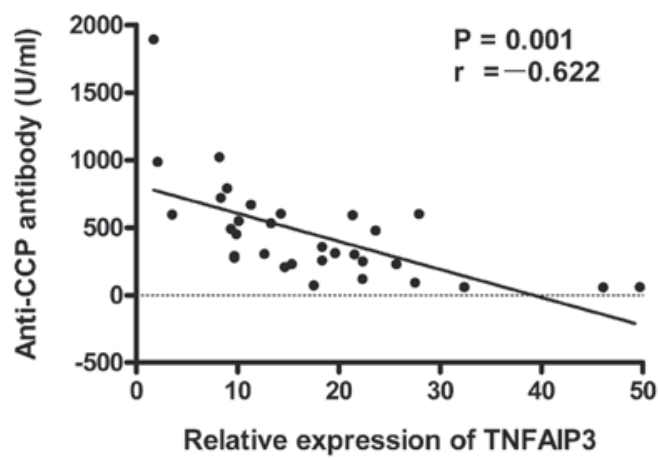

Figure 4. Negative correlation between the tumor necrosis factor $\alpha$-induced protein-3 (TNFAIP3) mRNA expression levels and anti-cyclic citrullinated peptide (CCP) antibody levels for the patients with a positive result of anti-CCP antibody $(\mathrm{n}=32)$.

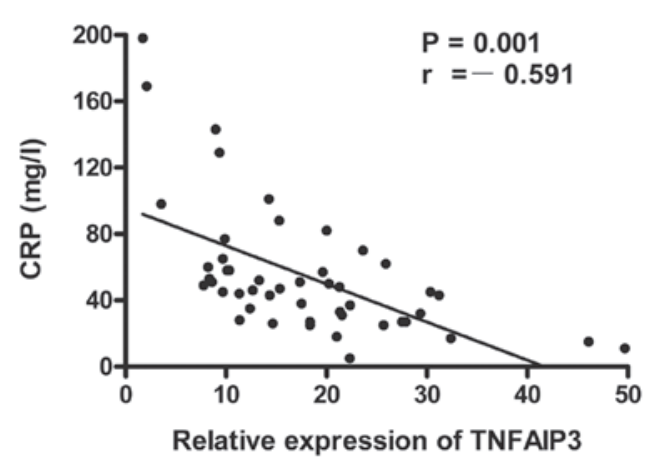

Figure 5. Negative correlation between the tumor necrosis factor $\alpha$-induced protein-3 (TNFAIP3) mRNA expression levels and C-reactive protein (CRP) levels for all the rheumatoid arthritis patients $(n=48)$.

patients with RA. Association of TNFAIP3 with demographic characteristics, clinical manifestations and laboratory parameters were analyzed. The results showed that the expression level of TNFAIP3 mRNA was negatively correlated with the RA score ( $\mathrm{r}=-0.596, \mathrm{P}=0.001$; Fig. 3), anti-CCP antibodies $(\mathrm{r}=-0.622, \mathrm{P}=0.001$; Fig. 4) and CRP $(\mathrm{r}=-0.591, \mathrm{P}=0.001$; Fig. 5) in RA patients. No statistically significant associations were identified between TNFAIP3 mRNA expression levels and other characteristics, clinical manifestations or laboratory parameters in the patients with RA. 


\section{Discussion}

RA is a chronic destructive disease of the joints that is characterized by hyperplastic synovitis due to resistance to apoptosis, infiltration of inflammatory cells into synovial tissue and joint destruction (21). As one of the NF- $\mathrm{BB}$ target genes, TNFAIP3 has been well established for its negative-feedback mechanism to block NF- $\mathrm{KB}$ activation through its ubiquitin-editing function in response to various inflammatory signaling, including TNF, IL-1 $\beta$ and lipopolysaccharides $(12,13,22,23)$. Inactivation of TNFAIP3 by the typical two mechanisms, deletions and inactivation mutations, has been reported in marginal zone lymphomas, Hodgkin's lymphoma, primary mediastinal B cell lymphoma and activated B cell-like diffuse large B cell lymphoma, which may contribute to lymphomagenesis $(24,25)$.

The TNFAIP3 gene plays a critical role in the negative regulation of immunity. To the best of our knowledge, this is the first study to report the downregulation of TNFAIP3 expression in RA patients and the negative correlation between TNFAIP3 expression and RA score, anti-CCP antibodies, CRP. The results suggest that the decreased expression of TNFAIP3 may be involved in the diagnosis and pathogenesis of RA.

The deficiency of TNFAIP3 expression may contribute to the pathogenesis of RA through several mechanisms. One of the possible mechanisms is that the insufficient expression of TNFAIP3 may cause hyperactivation of autoreactive T cell. TNFAIP3 has ubiquitinating and deubiquitinating enzymatic activity in the TNF receptor-signaling pathway (26). TNFAIP3 contains an $\mathrm{N}$-terminal domain that belongs to the ovarian tumor superfamily of deubiquitinating cysteine proteases and deubiquitinates K63-linked polyubiquitinated receptor-interacting protein, thereby blocking TNF- $\alpha$ induced NF- $\kappa B$ signaling (15). Since the TNFAIP3 gene has a function in limiting the activation of $\mathrm{T}$ cell by deubiquitinating mucosa-associated lymphoid tissue 1 to disrupt $\mathrm{T}$ cell receptor

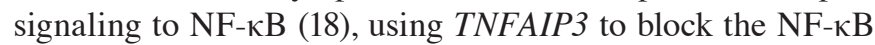
pathway in rheumatoid joints reduces the inflammatory response and the tissue destruction (26). TNFAIP3 decreased expression may induce $\mathrm{T}$ cell hyperactivation and the subsequent tissue damage occurring in RA patients. One of the major transcriptional circuits indicated in joint inflammation is the NF- $\kappa B$ pathway. Within the joints, activation of NF- $\kappa B$ leads to the expression of mediators of inflammation that include cytokines, chemokines and adhesion molecules (26). TNFAIP3 restricts B cell survival and prevents dendritic cell activation $(27,28)$. By contrast, TNFAIP3 deficiency in B cells enhances B cell proliferation (29) and results in the development of the immune complex. Therefore, the decreased expression of TNFAIP3 may lead to hyperactivation of $\mathrm{B}$ cells and accumulation of the immune complex.

In RA, NF- $\kappa \mathrm{B}$ regulates production of pro-inflammatory cytokines such as TNF- $\alpha$, IL- $1 \beta$ and IL- 6 , cell cycle progression, cell survival, adhesion and inhibition of apoptosis of FLS (30-32). Constitutive activation of NF- $\mathrm{KB}$ in certain autoimmune diseases, including RA, has been reported (33). One possible mechanism in this case is a defector insufficient activity of physiological I $\kappa$ B pathway, such as TNFAIP3 involved in a negative-feedback loop. As a result, the decreased expression of TNFAIP3 in RA patients may also contribute to a high serum level of proinflammatory cytokines, including TNF- $\alpha$, IL- $1 \beta$ and IL- 6 , which is another characteristic of RA. The major source of the proinflammatory cytokines is monocytes and macrophages. Myeloid-TNFAIP3-deficient mice have high levels of inflammatory cytokines in their serum, consistent with a sustained NF- $\kappa$ B activation and higher TNF- $\alpha$ production by the macrophages (34). Thus, the increased production of proinflammatory cytokines in RA may be partially ascribed to the insufficient expression of TNFAIP3.

Multiple polymorphisms in TNFAIP3 are closely associated with numerous pathological conditions, including systemic lupus erythematosus (SLE), coronary artery disease in type 2 diabetes, psoriasis and RA $(11,19,35,36)$. Several SNPs in the human TNFAIP3 locus are associated with increased susceptibility to type 1 diabetes, SLE, celiac disease, Crohn's disease, psoriasis, multiple sclerosis and RA (12), suggesting that defects in TNFAIP3 expression or activity could be involved in the development of specific autoimmune diseases (33). TNFAIP3 deficiency in myeloid cells triggers erosive polyarthritis resembling RA (33). Consequently, the downregulated expression of TNFAIP3 may give rise to RA disease, indicating a critical and cell-specific function in the etiology of RA.

The inverse correlation between TNFAIP3 expression and RA disease severity indicated by RA score, CRP, anti-CCP antibodies or RF suggest that the insufficient expression of TNFAIP3 may contribute to diagnosis and severity of the disease. The RA classification criteria and scoring system used is a global score, which was developed and validated for diagnostic purposes in RA. Therefore, the negative correlation between the TNFAIP3 mRNA expression and score in the RA patients means that the low expression of TNFAIP3 was associated with the diagnosis. Additionally, CRP, anti-CCP antibodies or RF are also indicators of the degree of inflammation and used to help diagnose disease. The level of TNFAIP3 expression may be an index of disease diagnosis since the TNFAIP3 mRNA expression was negatively correlated with the CRP, anti-CCP antibodies or RF in the RA patients. In addition, there was a significant difference in TNFAIP3 expression between patients with a positive result of anti-CCP antibodies and those with a negative result of anti-CCP antibodies. Antibodies to CCPs have been described in patients with RA and these appear to be the most specific markers of the disease. The association of TNFAIP3 expression with anti-CCP antibodies in RA patients also indicates reduction of TNFAIP3 expression, and was involved in diagnosis of RA disease. Taken together, the analysis of the association between TNFAIP3 expression and score, anti-CCP antibodies, RF and CRP further suggest a potential role of decreased TNFAIP3 expression in diagnosis of RA.

As for the causes of the low expression of TNFAIP3 in RA, there are several possible explanations. One reason may be polymorphisms of the TNFAIP3 gene $(18,19)$. In peripheral blood cells, no significant difference was detected in TNFAIP3 expression according to genotype at the intergenic markers rs6920220 and rs13207033 in RA patients or controls (37). For rs5029937 and rs7749323, TNFAIP3 expression was reduced in RA patients carrying the risk allele compared with $\mathrm{G} / \mathrm{G}$ in controls (37). For rs5029937 and rs7749423, the trend demonstrated that TNFAIP3 expression was reduced in healthy controls, suggesting a possible small allele-specific 
effect on TNFAIP3 expression (37). Therefore, the difference of TNFAIP 3 expression may be partially attributed to polymorphism of the TNFAIP3 gene. By contrast, to identify susceptibility alleles associated with RA, a genome-wide association study was carried out to identify genetic regions with potential DNA variants determining susceptibility to RA $(18,38)$. Two SNPs were unequivocally identified at $6 \mathrm{q} 23$. Although these variants are not located in a gene, they are thought to influence TNFAIP3 as its nearest gene $(\sim 150 \mathrm{~kb}$ downstream of TNFAIP3), possibly by the presence of potential regulatory DNA elements in this region (12).

The other possible reason is promoter methylation of the TNFAIP3 gene. TNFAIP3 is targeted by promoter methylation in certain hematological malignancies (39). Thus, the low expression of the TNFAIP3 gene in RA may be due in part to its aberrant methylation. This requires further investigation. The present study is limited by the sole RT-qPCR method in the measurement of TNFAIP 3 expression and lacks protein and mechanistic data. Quantification of the TNFAIP3 protein by flow cytometry or western blot analysis, as well as demonstration of the mechanism, will be an emphasis in future studies.

In conclusion, TNFAIP3 mRNA expression was downregulated and inversely correlated with certain disease parameters in RA patients. The results suggest that reduction of TNFAIP 3 expression may correlate with the diagnosis of RA. The data provide the support that the TNFAIP3 gene may be a target for gene therapy or pharmacological agents of RA disease.

\section{References}

1. Firestein GS: Evolving concepts of rheumatoid arthritis Nature 423: 356-361, 2003.

2. Iwamoto T, Okamoto H, Toyama Y and Momohara S: Molecular aspects of rheumatoid arthritis: Chemokines in the joints of patients. FEBS J 275: 4448-4455, 2008.

3. Li D, Wang L, Fan Y, Song L, Guo C, Zhu F, Zhang L and Shi Y: Down-regulation of A20 mRNA expression in peripheral blood mononuclear cells from patients with systemic lupus erythematosus. J Clin Immunol 32: 1287-1291, 2012.

4. Apostolidis SA, Lieberman LA, Kis-Toth K, Crispín JC and Tsokos GC: The dysregulation of cytokine networks in systemic lupus erythematosus. J Interferon Cytokine Res 31: 769-779, 2011.

5. Geiler J, Buch M and McDermott MF: Anti-TNF treatment in rheumatoid arthritis. Curr Pharm Des 17: 3141-3154, 2011.

6. Silverman $\mathrm{N}$ and Maniatis T: NF-kappaB signaling pathways in mammalian and insect innate immunity. Genes Dev 15 2321-2342, 2001

7. Verma IM, Stevenson JK, Schwarz EM, Van Antwerp D and Miyamoto S: Rel/NF-kappa B/I kappa B family: Intimate tales of association and dissociation. Genes Dev 9: 2723-2735, 1995.

8. Cavalcante LO, Melo MR, Dinis VG, Castro RB, Souza BD and Longui CA: Quantitation of glucocorticoid receptor alpha and NF- $\mathrm{B}$ pathway mRNA and its correlation with disease activity in rheumatoid arthritis patients. Genet Mol Res 9: 2300-2310, 2010.

9. Criswell LA: Gene discovery in rheumatoid arthritis highlights the CD40/NF-kappaB signaling pathway in disease pathogenesis. Immunol Rev 233: 55-61, 2010.

10. Simmonds RE and Foxwell BM: Signalling, inflammation and arthritis: NF-kappaB and its relevance to arthritis and inflammation. Rheumatology (Oxford) 47: 584-590, 2008.

11. Elsby LM, Orozco G, Denton J, Worthington J, Ray DW and Donn RP: Functional evaluation of TNFAIP3 (A20) in rheumatoid arthritis. Clin Exp Rheumatol 28: 708-714, 2010.

12. Vereecke L, Beyaert R and van Loo G: The ubiquitin-editing enzyme A20 (TNFAIP3) is a central regulator of immunopathology. Trends Immunol 30: 383-391, 2009.
13. Coornaert B, Carpentier I and Beyaert R: A20: Central gatekeeper in inflammation and immunity. J Biol Chem 284: 8217-8221, 2009.

14. Kingeter LM, Paul S, Maynard SK, Cartwright NG and Schaefer BC: Cutting edge: TCR ligation triggers digital activation of NF-kappaB. J Immunol 185: 4520-4524, 2010.

15. Düwel M, Welteke V, Oeckinghaus A, Baens M, Kloo B, Ferch U, Darnay BG, Ruland J, Marynen P and Krappmann D: A20 negatively regulates $\mathrm{T}$ cell receptor signaling to NF-kappaB by cleaving Malt1 ubiquitin chains. J Immunol 182: 7718-7728, 2009.

16. Lee EG, Boone DL, Chai S, Libby SL, Chien M, Lodolce JP and $\mathrm{Ma} \mathrm{A}$ : Failure to regulate TNF-induced NF-kappaB and cell death responses in A20-deficient mice. Science 289: 2350-2354, 2000.

17. Orozco G, Hinks A, Eyre S, et al; Wellcome Trust Case Control Consortium; YEAR consortium: Combined effects of three independent SNPs greatly increase the risk estimate for RA at $6 \mathrm{q} 23$. Hum Mol Genet 18: 2693-2699, 2009.

18. Musone SL, Taylor KE, Lu TT, Nititham J, Ferreira RC, Ortmann W, Shifrin N, Petri MA, Kamboh MI, Manzi S, et al: Multiple polymorphisms in the TNFAIP3 region are independently associated with systemic lupus erythematosus. Nat Genet 40: 1062-1064, 2008

19. Thomson W, Barton A, Ke X, Eyre S, Hinks A, Bowes J, Donn R, Symmons D, Hider S, Bruce IN, et al; Wellcome Trust Case Control Consortium; YEAR Consortium: Rheumatoid arthritis association at 6q23. Nat Genet 39: 1431-1433, 2007.

20. Aletaha D, Neogi T, Silman AJ, Funovits J, Felson DT, Bingham CO III, Birnbaum NS, Burmester GR, Bykerk VP, Cohen MD, et al: 2010 Rheumatoid arthritis classification criteria: An American College of Rheumatology/European League Against Rheumatism collaborative initiative. Arthritis Rheum 62: 2569-2581, 2010.

21. Hah YS, Lee YR, Jun JS, Lim HS, Kim HO, Jeong YG, Hur GM, Lee SY, Chung MJ, Park JW, et al: A20 suppresses inflammatory responses and bone destruction in human fibroblast-like synoviocytes and in mice with collagen-induced arthritis. Arthritis Rheum 62: 2313-2321, 2010.

22. Boone DL, Turer EE, Lee EG, Ahmad RC, Wheeler MT, Tsui C, Hurley P, Chien M, Chai S, Hitotsumatsu O, et al: The ubiquitin-modifying enzyme A20 is required for termination of Toll-like receptor responses. Nat Immunol 5: 1052-1060, 2004.

23. Renner F and Schmitz ML: Autoregulatory feedback loops terminating the NF-kappaB response. Trends Biochem Sci 34: 128-135, 2009.

24. Kato M, Sanada M, Kato I, et al: Frequent inactivation of A20 in B-cell lymphomas. Nature 459: 712-716, 2009.

25. Schmitz R, Hansmann ML, Bohle V, Martin-Subero JI, Hartmann S, Mechtersheimer G, Klapper W, Vater I, Giefing M, Gesk S, et al: TNFAIP3 (A20) is a tumor suppressor gene in Hodgkin lymphoma and primary mediastinal B cell lymphoma. J Exp Med 206: 981-989, 2009.

26. Heyninck K and Beyaert R: A20 inhibits NF-kappaB activation by dual ubiquitin-editing functions. Trends Biochem Sci 30: 1-4, 2005.

27. Tavares RM, Turer EE, Liu CL, Advincula R, Scapini P, Rhee L, Barrera J, Lowell CA, Utz PJ, Malynn BA, et al: The ubiquitin modifying enzyme A20 restricts B cell survival and prevents autoimmunity. Immunity 33: 181-191, 2010

28. Kool M, van Loo G, Waelput W, De Prijck S, Muskens F, Sze M, van Praet J, Branco-Madeira F, Janssens S, Reizis B, et al: The ubiquitin-editing protein A20 prevents dendritic cell activation, recognition of apoptotic cells, and systemic autoimmunity. Immunity 35: 82-96, 2011.

29. Hövelmeyer N, Reissig S, Xuan NT, Adams-Quack P, Lukas D, Nikolaev A, Schlüter D and Waisman A: A20 deficiency in B cells enhances B-cell proliferation and results in the development of autoantibodies. Eur J Immunol 41: 595-601, 2011.

30. Handel ML, McMorrow LB and Gravallese EM: Nuclear factor-kappa B in rheumatoid synovium. Localization of p50 and p65. Arthritis Rheum 38: 1762-1770, 1995.

31. Marok R, Winyard PG, Coumbe A, Kus ML, Gaffney K, Blades S, Mapp PI, Morris CJ, Blake DR, Kaltschmidt C, et al: Activation of the transcription factor nuclear factor-kappaB in human inflamed synovial tissue. Arthritis Rheum 39: 583-591, 1996.

32. Brown KD, Claudio E and Siebenlist U: The roles of the classical and alternative nuclear factor-kappaB pathways: Potential implications for autoimmunity and rheumatoid arthritis. Arthritis Res Ther 10: 212, 2008. 
33. Vereecke L, Beyaert R and van Loo G: Genetic relationships between A20/TNFAIP3, chronic inflammation and autoimmune disease. Biochem Soc Trans 39: 1086-1091, 2011.

34. Matmati M, Jacques P, Maelfait J, Verheugen E, Kool M, Sze M, Geboes L, Louagie E, Mc Guire C, Vereecke L, et al: A20 (TNFAIP3) deficiency in myeloid cells triggers erosive polyarthritis resembling rheumatoid arthritis. Nat Genet 43: 908-912, 2011.

35. Boonyasrisawat W, Eberle D, Bacci S, Zhang YY, Nolan D, Gervino EV, Johnstone MT, Trischitta V, Shoelson SE and Doria A: Tag polymorphisms at the A20 (TNFAIP3) locus are associated with lower gene expression and increased risk of coronary artery disease in type 2 diabetes. Diabetes 56: 499-505, 2007.

36. Tejasvi T, Stuart PE, Chandran V, Voorhees JJ, Gladman DD, Rahman P, Elder JT and Nair RP: TNFAIP3 gene polymorphisms are associated with response to TNF blockade in psoriasis. J Invest Dermatol 132: 593-600, 2012.
37. Maxwell JR, Gowers IR, Kuet KP, Barton A, Worthington J and Wilson AG: Expression of the autoimmunity associated TNFAIP3 is increased in rheumatoid arthritis but does not differ according to genotype at 6q23. Rheumatology (Oxford) 51: $1514-1515,2012$.

38. Plenge RM, Cotsapas C, Davies L, Price AL, de Bakker PI, Maller J, Pe'er I, Burtt NP, Blumenstiel B, DeFelice M, et al: Two independent alleles at $6 \mathrm{q} 23$ associated with risk of rheumatoid arthritis. Nat Genet 39: 1477-1482, 2007.

39. Frenzel LP, Claus R, Plume N, Schwamb J, Konermann C, Pallasch CP, Claasen J, Brinker R, Wollnik B, Plass C, et al: Sustained NF-kappaB activity in chronic lymphocytic leukemia is independent of genetic and epigenetic alterations in the TNFAIP3 (A20) locus. Int J Cancer 128: 2495-2500, 2011. 